\title{
Obesity parameters in relation to lung function levels in a large Chinese rural adult population
}

\author{
Xiang Zeng ${ }^{1,2 *}$, Dongling Liü ${ }^{3 *}$, Zhen An ${ }^{1}$, Huijun $\mathrm{Li}^{1}$, Jie Song ${ }^{1}$, Weidong $\mathrm{Wu}^{1}$ \\ ${ }^{1}$ School of Public Health, Xinxiang Medical University, Xinxiang, China; '2 Laboratory of Environmental Medicine and Developmental Toxicology, \\ Guangdong Key Laboratory of Environmental Pollution and Health, School of Environment, Jinan University, Guangzhou, China; ${ }^{3} \mathrm{Henan}$ Key \\ Laboratory of Medical Tissue Regeneration, Xinxiang Medical University, Xinxiang, China
}

OBJECTIVES: The association between obesity parameters and lung function indicators in the general Chinese rural adult population remains unclear.

METHODS: In total, 8,284 Chinese adults aged 20 years to 80 years old from Xinxiang were recruited. Obesity-related parameters, including body mass index (BMI), waist circumference (WC), hip circumference (HC), waist-to-hip ratio (WHR), waistto-height ratio (WHtR), body fat percentage (BFP), basal metabolism, and visceral fat index, and lung function parameters such as forced vital capacity and forced expiratory volume in first second were measured.

RESULTS: The total prevalence of obesity defined by BMI, WC, WHR, WHtR, and BFP was $23.2 \%, 58.2 \%, 66.7 \%, 69.2 \%$, and $56.5 \%$, respectively. Spearman correlation analyses showed significant correlations between all obesity-related parameters and lung function. Linear regression analyses further demonstrated that BMI, WHtR, BFP, and general obesity defined using those indicators were negatively associated with lung function, while WC, WHR, and central obesity defined accordingly were positively associated with lung function. The relationship between general obesity and lung function was more evident in women than in men, while the link between central obesity and lung function was more obvious in men than in women.

CONCLUSIONS: Obesity is closely related to lung function in the general Chinese adult population. Weight control and loss are important strategies to improve lung function and respiratory health.

KEY WORDS: Obesity, Body fat distribution, Overweight, Pulmonary function, Rural area, Chinese

\section{INTRODUCTION}

Obesity is a significant global public health challenge; its prevalence has grown considerably in recent years, to the point that it

\section{Correspondence: Weidong Wu}

School of Public Health, Xinxiang Medical University, 601 Jinsui Road, Xinxiang 453003, China

E-mail:wdwu2013@126.com

*Zeng \& Liu contributed equally to this work as joint first authors. Received: May 10, 2021 / Accepted: Aug 3, 2021 / Published: Aug 3, 2021

This article is available from: https://e-epih.org/

(c) This is an open-access article distributed under the terms of the Creative Commons Attribution License (https://creativecommons.org/licenses/by/4.0/), which permits unrestricted use, distribution, and reproduction in any medium, provided the original work is properly cited.

(C) 2021, Korean Society of Epidemiology has become a global pandemic accompanied by tremendous morbidity and mortality. It is estimated that more than one-third of adults are overweight or obese around the world [1], and the global prevalence of obesity will be 1.12 billion in 2030 [2]. Obesity and overweight caused approximately 3.4 million deaths worldwide in 2010 [3]. The epidemic of overweight and obesity is a major public health problem in China, although the problem is less severe than in developed countries [4-6]. In urban regions of China, the overall prevalence of overweight ranges from $15.7 \%$ to $41.8 \%$, and the prevalence of obesity ranges from $6.3 \%$ to $19.5 \%$ in adults [7-9]. Obesity is an important risk factor and modifier for metabolic disorders, cardiovascular disease, dyslipidemia, asthma, and cancer [10-12]. Previous studies have demonstrated that obesity may cause restrictive ventilation dysfunction by reducing lung and chest wall compliance due to excessive fat deposits in the diaphragm, chest wall, and abdominal cavity [11-15]. In 
addition, weight loss and exercise can help patients with obesityrelated lung disease reduce the resistance to respiration caused by excess fat [16-18]. However, relatively little is known regarding the detrimental influence of obesity on non-asthmatic respiratory conditions, particularly respiratory lung function and damage in the general Chinese rural population.

There are several commonly used indicators that reflect body fat distribution and define obesity, including body mass index (BMI), waist circumference (WC), hip circumference (HC), waistto-hip ratio (WHR), waist-to-height ratio (WHtR), body fat percentage (BFP), basal metabolism (BM), and visceral fat index (VFI) [19-23]. BMI has been frequently used to define general obesity, while WC, WHR, WHtR, and BFP have been commonly used to define abdominal obesity. Briefly, general obesity is defined as a BMI $\geq 25 \mathrm{~kg} / \mathrm{m}^{2}$ according to the World Health Organization recommendations for Asians [24]. In contrast, abdominal obesity (clinically known as central obesity) is defined as WC $\geq 90 \mathrm{~cm}$ for men and WC $\geq 80 \mathrm{~cm}$ for women, WHR $\geq 0.90$ for men and WHR $\geq 0.80$ for women, WHtR $\geq 0.5$ both for men and women, or BFP $\geq 25 \%$ for men and BFP $\geq 33 \%$ for women [19,23,25-27]. A strength of general obesity as a measure is that it is useful for classifying the severity of obesity, but it has weaknesses in terms of specificity, as it cannot distinguish between fat mass and lean mass or denote the pattern of regional fat distribution. Instead, abdominal or central obesity is closely related to central fat localization and all-cause mortality, independently of general obesity [28]. The deposition of fat in the thorax, abdomen, visceral organs, and an apple-like body shape are the main characteristics of central obesity. Systemic or peripheral obesity is characterized by the deposition of fat in the hips, thighs, limbs, subcutaneous tissue, and a pear-like body shape. The distinction between different types of obesity is important since central obesity tends to have a more direct impact on lung mechanics and metabolic inflammation than peripheral obesity [11]. Several feasible mechanisms have been proposed to explain how obesity affects respiratory impairment, such as decreased total respiratory system compliance, increased airway resistance, reduced lung volume, and altered ventilation and gas exchange $[4,11,13]$.

Inconsistent relationships between obesity and lung function have been reported in studies of populations with different conditions and backgrounds [29-39]. For instance, there is a higher metabolic risk in Asians than in Caucasians at a given BMI level [37]. To date, there is still a lack of comparative studies analyzing the relationship between different obesity parameters and lung function within the same study. Therefore, we conducted a crosssectional study on rural residents of China, analyzed big data, and aimed to further confirm the relationship between several obesity parameters and lung function indicators in the adult population in central China. Clinicians should be alert to the possible adverse effects of obesity on lung function, and weight control and body shape management should be addressed in the prevention and improvement of respiratory disease.

\section{MATERIALS AND METHODS}

\section{Study sites and participants}

This study was conducted in rural areas in Xinxiang County, Henan Province, China (Supplementary Material 1). The inclusion criteria were subjects with no acute disease or hospitalization experience within 1 month who were not pregnant during the period of investigation. A total of 8,375 subjects aged $20-80$ years met the inclusion criteria and were subsequently screened from several villages in 2 towns (Qiliying and Langgongmiao) in Xinxiang County using a cluster sampling method (Supplementary Material 1). Ninety-one subjects were excluded because that they were unable to complete the lung function test. Therefore, 8,284 adults were finally included in the analyses of this study. The participants completed a general health questionnaire and underwent a routine physical examination.

\section{Questionnaire}

Participants were required to complete a questionnaire through face-to-face conversations with trained staff. Physical measurements were conducted using standardized procedures as described below. The questionnaire collected basic individual information including age, gender, marital status, residential address, income, education, and lifestyle characteristics (e.g., smoking status and alcohol consumption). The physical examination parameters included body height, weight, WC, HC, BFP, BM, and VFI [19].

\section{Physical measurements}

All participants underwent weight, height, waist, hip, BFP, BM, and VFI measurements according to a standard protocol [20]. The physical examination was performed after participants had taken off their shoes and heavy clothes. Weight was measured to the nearest $0.1 \mathrm{~kg}$, and height was measured to 1 decimal point. WC was determined to the nearest $0.5 \mathrm{~cm}$ around the abdomen at the level of the umbilicus/belly button and HC. HC was read to the nearest $0.5 \mathrm{~cm}$ at the fullest part between the abdomen and groin. BMI was defined as weight $(\mathrm{kg})$ divided BM, by height squared $\left(\mathrm{m}^{2}\right)$. WHR was calculated as WC divided by HC. WHtR was calculated as WC divided by height. BFP, and VFI were measured using Omron HBF371 (Omron, Kyoto, Japan) body fat and weight measurement scales using bioelectrical impedance analysis. Specifically, human body resistance was measured by a weak current flowing through hands and feet, and the characteristic of the human body. In other words, human issue with more water is easy to conduct electrcity, while adipose tissue is hardly conductive. BM was automatically calculated using the formula provided with the scales, which mainly depend on gender, weight and body fat. BFP was defined as the body fat weight divided by total weight. All measurements were taken twice and the average of the 2 values was used in further analyses [19].

\section{Definition of obesity}

General obesity was defined as a BMI $\geq 25 \mathrm{~kg} / \mathrm{m}^{2}[24,33]$. Central obesity was defined as WC $\geq 90 \mathrm{~cm}$ for men and $W C \geq 80 \mathrm{~cm}$ 
Zeng X et al. : Obesity and lung function

for women, WHR $\geq 0.90$ for men and WHR $\geq 0.80$ for women, or WHtR $\geq 0.5$ for both men and women [23]. Obesity was defined as BFP $\geq 25 \%$ for men and BFP $\geq 33 \%$ for women [27]. VFI was divided into four categories (from "thin" to "high") according to the criteria used in a previous study, respectively [40].

\section{Spirometry}

The lung function test was conducted with a portable spirometer (Chestgraph HI-801; Chest MI, Tokyo, Japan) with participants in a standing position following the standardized procedures of the American Thoracic Society criteria, with at least 3 measurements. The analyses used the highest value of forced vital capacity (FVC), forced expiratory volume in the first second $\left(\mathrm{FEV}_{1}\right)$, vital capacity (VC), inspiratory capacity (IC), residual volume (RV), tidal volume (TV), expiratory reserve volume (ERV), inspiratory reserve volume (IRV), total lung capacity (TLC), peak inspiratory flow (PIF), peak expiratory flow (PEF), and peak expiratory flow time (PEFT) [41]. The spirometer was calibrated before each test according to the manufacturer's instructions. The predicted values for $\mathrm{FVC}$ and $\mathrm{FEV}_{1}$ were calculated based on the equations for the Chinese adult population [42]. The main outcome variables were lung function and its predicted values, as well as restrictive respiratory defects [43].

\section{Statistical analysis}

All data were entered using EpiData version 3.0. The statistical analysis was performed using IBM SPSS version 22.0 (IBM Corp., Armonk, NY, USA). Normally distributed continuous variables were presented as the mean \pm standard deviation and compared using the t-test. Non-normally distributed quantitative data were displayed as median and interquartile range and compared using the Mann-Whitney U test. Categorical variables were expressed as percentages and were analyzed using the chi-square test or Fisher exact test as appropriate. Spearman correlation analysis was used to explore the correlations between obesity and lung function parameters. Multivariate linear regression analyses were further carried out to evaluate the associations between obesity and lung function. Potential confounders were included in each full model when the p-value of the confounder was lower than 0.05 . A p-value $<0.05$ was considered to indicate statistical significance.

\section{Ethics statement}

Participants provided written informed consent. The study was approved by the Medical Ethics Committee of the Xinxiang Medical University, Xinxiang, China. This study was conducted ethically in accordance with the World Medical Association Declaration of Helsinki. All participants provided written informed consent before enrollment and data collection.

\section{RESULTS}

\section{General characteristics of the study population}

The average age of the participants was $52.12 \pm 12.42$ years for men and $51.23 \pm 12.09$ years for women. The proportion of men
Table 1. Demographic characteristics of the study population

\begin{tabular}{|c|c|c|c|}
\hline Characteristics & $\begin{array}{c}\text { Men } \\
(n=3,327)\end{array}$ & $\begin{array}{l}\text { Women } \\
(n=4,957)\end{array}$ & p-value \\
\hline Age, mean $\pm S D(y r)$ & $52.12 \pm 12.42$ & $51.23 \pm 12.09$ & $0.009^{1}$ \\
\hline Smoking & & & $<0.001^{2}$ \\
\hline Never smokers & $1,095(32.9)$ & $4,904(98.9)$ & \\
\hline Ex-smokers/former smokers & $586(17.6)$ & $13(0.3)$ & \\
\hline Current smokers & $1,645(49.5)$ & $39(0.8)$ & \\
\hline Drinking & & & $<0.001^{2}$ \\
\hline Never drinkers & $1,336(40.2)$ & $4,848(97.8)$ & \\
\hline Ex-drinkers/former drinkers & $294(8.8)$ & $11(0.2)$ & \\
\hline Current drinkers & $1,696(51.0)$ & $97(2.0)$ & \\
\hline $\begin{array}{c}\text { Family monthly income level } \\
\text { per capita (Chinese yuan) }\end{array}$ & & & $<0.001^{2}$ \\
\hline$<500$ & $971(29.2)$ & $1,569(31.7)$ & \\
\hline $500-999$ & $1,183(35.6)$ & $1,804(36.4)$ & \\
\hline $1,000-1,999$ & $735(22.1)$ & $1,103(22.3)$ & \\
\hline $2,000-2,999$ & $238(7.2)$ & $294(6.0)$ & \\
\hline$\geq 3,000$ & $197(5.9)$ & $175(3.5)$ & \\
\hline Education level & & & $<0.001^{2}$ \\
\hline Illiteracy & $115(3.5)$ & $599(12.1)$ & \\
\hline Primary school & $577(17.3)$ & $1,073(21.6)$ & \\
\hline Middle school & $1,490(44.8)$ & $1,988(40.1)$ & \\
\hline $\begin{array}{l}\text { Secondary school or high } \\
\text { school }\end{array}$ & $890(26.8)$ & $953(19.2)$ & \\
\hline College/university and above & $254(7.6)$ & $341(6.9)$ & \\
\hline
\end{tabular}

Values are presented as number (\%).

SD, standard deviation.

${ }^{1}$ Analysis by the independent-sample t-test.

${ }^{2}$ Analysis by the chi-square test.

and women was $40.2 \%$ and $59.8 \%$, respectively. As shown in Table 1, men had higher current smoking and drinking rates, family income, and educational levels than women (Table 1). There was no significant difference in BMI between men and women (Supplementary Material 2). However, the height, weight, WC, HC, WHR, BM and VFI of men were higher than those of women, whereas the WHtR and BFP of men were lower than those of women (Table 2).

\section{Prevalence of obesity}

The total prevalence of obesity as defined by BMI, WC, WHR, $\mathrm{WHtR}$, and BFP was $23.2 \%, 58.2 \%, 66.7 \%, 69.2 \%$, and $56.5 \%$, respectively. In addition to the prevalence of obesity defined by BMI and $\mathrm{WHtR}$, which are height-related parameters, the prevalence of obesity defined using several other indicators such as WC (65.0\%), WHR (80.2\%), and BFP (58.3\%) was higher in women than in men (48.0, 58.4, and 53.7\%), respectively (Figure 1). In total, 1,891 (22.8\%) participants had both general and central obesity. In other words, the prevalence of obesity defined by BMI and WHtR was not higher in women than in men, whereas the prevalence of obesity defined by WC, WHR, and BFP was higher in women than in men (Figure 1) (Supplementary Material 3). WC, WHR (as a 
Table 2. Levels of obesity and lung function parameters in the adult population from Qiliying and Langgongmiao in Xinxiang County, China

\begin{tabular}{|c|c|c|c|}
\hline Characteristics & Men $(n=3,327)$ & Women $(n=4,957)$ & $\mathrm{p}$-value \\
\hline \multicolumn{4}{|c|}{ Lung function parameters } \\
\hline $\mathrm{FVC}(\mathrm{L})$ & $3.87 \pm 0.50$ & $2.72 \pm 0.40$ & $<0.001^{1}$ \\
\hline FVC predicted (L) & $3.73 \pm 0.49$ & $2.67 \pm 0.34$ & $<0.001^{1}$ \\
\hline $\mathrm{FEV}_{1}(\mathrm{~L})$ & $3.18 \pm 0.54$ & $2.34 \pm 0.43$ & $<0.001^{1}$ \\
\hline $\mathrm{FEV}_{1}$ predicted $(\mathrm{L})$ & $2.98 \pm 0.47$ & $2.16 \pm 0.33$ & $<0.001^{1}$ \\
\hline $\mathrm{FEV}_{1} / \mathrm{FVC}$ & $0.81(0.79-0.84)$ & $0.85(0.83-0.87)$ & $<0.001^{2}$ \\
\hline VC (L) & $3.68 \pm 0.34$ & $2.64 \pm 0.27$ & $<0.001^{1}$ \\
\hline IC (L) & $2.12 \pm 0.73$ & $1.64 \pm 0.61$ & $<0.001^{1}$ \\
\hline $\mathrm{RV}(\mathrm{L})$ & $1.56 \pm 0.15$ & $1.59 \pm 0.18$ & $<0.001^{1}$ \\
\hline TV (L) & $0.61(0.43-0.84)$ & $0.48(0.33-0.67)$ & $<0.001^{2}$ \\
\hline ERV (L) & $0.93(0.58-1.30)$ & $0.56(0.32-0.82)$ & $<0.001^{2}$ \\
\hline IRV (L) & $1.45(1.07-1.87)$ & $1.15(0.80-1.45)$ & $<0.001^{2}$ \\
\hline TLC (L) & $5.57 \pm 0.34$ & $4.04 \pm 0.28$ & $<0.001^{1}$ \\
\hline RV/TLV (\%) & $30.4(26.9-33.7)$ & $28.9(26.5-31.0)$ & $<0.001^{2}$ \\
\hline PIF (L/sec) & $2.08(1.55-2.76)$ & $1.79(1.36-2.33)$ & $<0.001^{2}$ \\
\hline PEF (L/sec) & $8.40(7.94-8.87)$ & $5.96(5.65-6.29)$ & $<0.001^{2}$ \\
\hline PEFT (sec) & $0.25(0.16-0.42)$ & $0.27(0.18-0.42)$ & $<0.001^{2}$ \\
\hline \multicolumn{4}{|c|}{ Physical parameters } \\
\hline Height $(\mathrm{cm})$ & $168.66 \pm 6.43$ & $157.44 \pm 5.88$ & $<0.001^{1}$ \\
\hline Weight (kg) & $72.90 \pm 11.51$ & $63.29 \pm 10.02$ & $<0.001^{1}$ \\
\hline BMI $\left(\mathrm{kg} / \mathrm{m}^{2}\right)$ & $25.60(23.14-28.03)$ & $25.16(22.96-27.44)$ & $0.106^{2}$ \\
\hline WC $(\mathrm{cm})$ & $91.39 \pm 7.02$ & $87.19 \pm 9.36$ & $<0.001^{1}$ \\
\hline $\mathrm{HC}(\mathrm{cm})$ & $98.03 \pm 6.56$ & $97.23 \pm 7.49$ & $<0.001^{1}$ \\
\hline WHR & $0.914(0.867-0.960)$ & $0.867(0.813-0.922)$ & $<0.001^{2}$ \\
\hline WHtR & $0.533(0.491-0.572)$ & $0.539(0.490-0.585)$ & $0.002^{2}$ \\
\hline BFP & $25.6(22.2-28.8)$ & $34.1(30.6-37.0)$ & $<0.001^{2}$ \\
\hline BM (kcal) & $1,626.01 \pm 188.68$ & $1,304.15 \pm 165.55$ & $<0.001^{1}$ \\
\hline VFI & $12.43 \pm 5.11$ & $8.47 \pm 4.51$ & $<0.001^{1}$ \\
\hline
\end{tabular}

Values are presented as mean \pm standard deviation (normal distribution data) or median values with interquartile (non-normal distribution data). FVC, forced vital capacity; FEV , forced expiratory volume in 1 second; VC, vital capacity; IC, inspiratory capacity; RV, residual volume; TV, tidal volume; ERV, expiratory reserve volume; IRV, inspiratory reserve volume; TLC, total lung capacity; TLV, total lung volume; PIF, peak inspiratory flow; PEF, peak expiratory flow; PEFT, peak expiratory flow time; $\mathrm{BMI}$, body mass index; WC, waist circumference; $\mathrm{HC}$, hip circumference; WHR, waist-to-hip ratio; WHtR, waist-to-height ratio; $\mathrm{BFP}$, body fat percentage; $\mathrm{BM}$, basal metabolism; $\mathrm{VFI}$, visceral fat index.

${ }^{1}$ Analysis by the independent-sample t-test.

${ }^{2}$ Analysis by the Mann-Whitney $\mathrm{U}$ test.

parameter positively related to WC), and obesity defined accordingly were higher in women than in men. Instead, BMI and WHtR (as parameters negatively related to height) and obesity defined accordingly were higher in men than in women. Therefore, women's higher WC and shorter height may contribute to their high prevalence of obesity when compared with men.

\section{Lung function levels}

Both FVC and $\mathrm{FEV}_{1}$ and their predicted values were higher in men than those in women (Table 2). In addition, participants' FVC

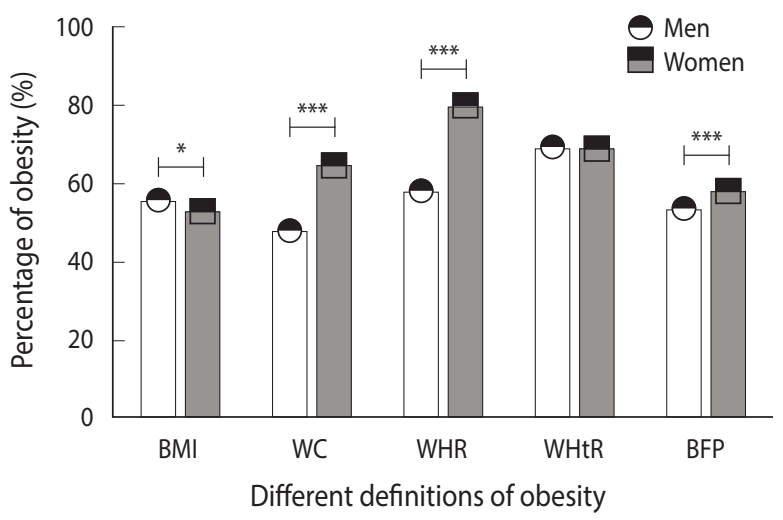

Figure 1. Comparison of the prevalence of obesity between men $(n=3,327)$ and women $(n=4,957)$. BMl, body mass index; WC, waist circumference; $\mathrm{HC}$, hip circumference; WHR, waist-to-hip ratio; WHtR, waist-to-height ratio; BFP, body fat percentage. The average percentages of obesity are displayed as mean \pm standard deviation, and the error bar in the figure represents the standard deviation. ${ }^{*} \mathrm{p}<0.05,{ }^{* * *} \mathrm{p}<0.001$.

and $\mathrm{FEV}_{1}$ were higher than their predicted values. Similarly, most lung function indices, such as FVC, FEV $\mathrm{F}_{1}, \mathrm{VC}, \mathrm{IC}, \mathrm{RV}, \mathrm{TV}, \mathrm{ERV}$, IRV, TLC, PIF, and PEF, were significantly higher in men than those of women (Table 2). However, the ratio of FVC to $\mathrm{FEV}_{1}$ $\left(\mathrm{FEV}_{1} / \mathrm{FVC}\right)$ was higher in women than that in men (Table 2). Moreover, the FVC and $\mathrm{FEV}_{1}$ of participants were significantly lower in the obesity groups than in the non-obesity groups for all definitions of obesity (Figure 2) (Supplementary Material 4).

\section{Correlation between obesity parameters and lung function indicators}

Spearman correlation analyses demonstrated that several obesity parameters were significantly correlated with lung function levels (Table 3). BMI, WHtR, BFP, and VFI were negatively correlated with FVC and $\mathrm{FEV}_{1}$. However, WC, HC, WHR, and BM were positively correlated with FVC and $\mathrm{FEV}_{1}$ (Figure 3) (Supplementary Material 5). Both men and women displayed a similar direction of correlation between obesity parameters and lung function levels. In addition, BMI, WC, WHR, WHtR, BFP, BM, and VFI were negatively correlated with the ratio of $\mathrm{FVC}$ to $\mathrm{FEV}_{1}$ $\left(\mathrm{FEV}_{1} / \mathrm{FVC}\right)$, while height and $\mathrm{HC}$ were positively correlated with $\mathrm{FEV}_{1} / \mathrm{FVC}$ (Table 3 ). In addition, obesity parameters including BMI, WC, HC, WHR, WHtR, BFP, BM, and VFI were significantly correlated with most of the other lung function indicators, such as VC, IC, RV, TV, ERV, IRV, TLC, PIF, PEF, and PEFT (Supplementary Material 5). Remarkably, general obesity was more closely related to lung function in women than in men, while central obesity was more evident in men than in women (Table 3) (Supplementary Materials 5 and 6). Specifically, most obesity parameters such as BMI, WC, WHR, WHtR, and BFP were negatively correlated with lung function in women. However, this trend was not consistently evident in men. For example, in men, BMI was negatively correlated with $\mathrm{FVC}$ and $\mathrm{FEV}_{1}$, while WC was positive- 

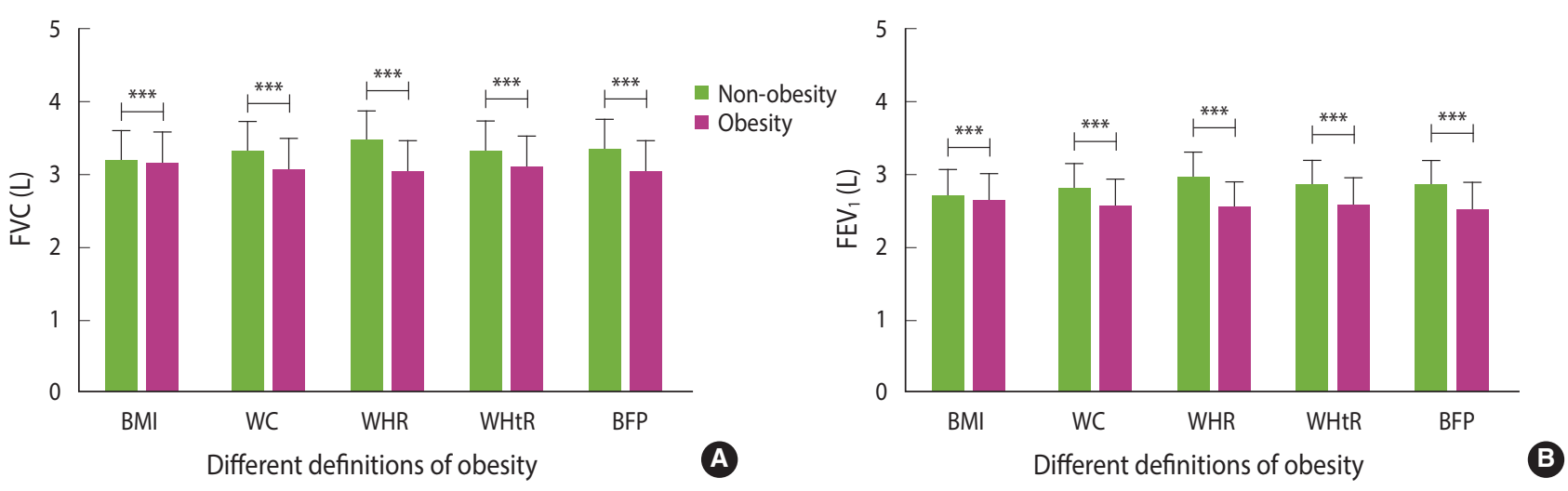

Figure 2. Comparison of FVC $(A)$ and $F E V_{1}(B)$ between non-obese and obese subjects. FVC, forced vital capacity; FEV ${ }_{1}$, forced expiratory volume in 1 second; BMI, body mass index; WC, waist circumference; WHR, waist-to-hip ratio; WHtR, waist-to-height ratio; BFP, body fat percentage. The comparison of FVC and FEV 1 between obesity and non-obesity groups was made using the independent-sample t-test. The average levels of lung function are displayed as mean \pm standard deviation, and the error bar in this figure represents the standard deviation. ${ }^{* * *} \mathrm{p}<0.001$.

Table 3. Spearman correlation coefficients between obesity parameters and lung function indicators in the adult population from Xinxiang County, China $(n=8,284)$

\begin{tabular}{|c|c|c|c|c|c|c|}
\hline \multirow{2}{*}{ Variables } & \multicolumn{3}{|c|}{ Men } & \multicolumn{3}{|c|}{ Women } \\
\hline & FVC & $\mathrm{FEV}_{1}$ & $\mathrm{FEV}_{1} / \mathrm{FVC}$ & FVC & $\mathrm{FEV}_{1}$ & $\mathrm{FEV}_{1} / \mathrm{FVC}$ \\
\hline Height & $0.742^{* * *}$ & $0.713^{* * *}$ & $0.357^{* * *}$ & $0.718^{* * *}$ & $0.709 * * *$ & $0.503^{* * *}$ \\
\hline Weight & $0.329 * * *$ & $0.333^{* * *}$ & $0.210^{* * *}$ & $0.166^{* * *}$ & $0.143^{* * *}$ & $0.063^{* * *}$ \\
\hline BMI & -0.018 & -0.001 & $-0.051^{* * *}$ & $-0.172^{* * *}$ & $-0.193^{* * *}$ & $-0.178^{* * *}$ \\
\hline WC & 0.033 & 0.033 & 0.016 & $-0.234^{* * *}$ & $-0.265^{* * *}$ & $-0.285^{* * *}$ \\
\hline $\mathrm{HC}$ & $0.148^{* * *}$ & $0.185^{* *}$ & $0.177^{* * *}$ & $0.083^{* * * *}$ & $0.084^{* * * *}$ & $0.074^{* * *}$ \\
\hline WHR & $-0.077^{* * * *}$ & $-0.107^{* * *}$ & $-0.122^{* * * *}$ & $-0.377^{* * *}$ & $-0.419^{* * *}$ & $-0.436^{* * *}$ \\
\hline WHtR & $-0.208^{* * *}$ & $-0.199^{* * *}$ & $-0.097^{* * *}$ & $-0.429^{* * * *}$ & $-0.456^{* * *}$ & $-0.412^{* * * *}$ \\
\hline BFP & $-0.229 * * *$ & $-0.249 * * *$ & $-0.216^{* * *}$ & $-0.470 * * *$ & $-0.500 * * *$ & $-0.469 * * *$ \\
\hline BM & $0.410^{* * *}$ & $0.422^{* * *}$ & $0.291^{* * *}$ & $0.270^{* * *}$ & $0.250^{* * *}$ & $0.165^{* * *}$ \\
\hline VFI & $-0.233^{* * *}$ & $-0.240^{* * *}$ & $-0.184^{* * *}$ & $-0.370^{* * *}$ & $-0.400^{* * *}$ & $-0.377^{* * *}$ \\
\hline
\end{tabular}

FVC, forced vital capacity; FEV 1 , forced expiratory volume in 1 second; BMI, body mass index; WC, waist circumference; HC, hip circumference; WHR, waist-to-hip ratio; WHtR, waist-to-height ratio; $\mathrm{BFP}$, body fat percentage; $\mathrm{BM}$, basal metabolism; $\mathrm{VFI}$, visceral fat index. ${ }^{* *} \mathrm{p} \leq 0.01,{ }^{* * *} \mathrm{p} \leq 0.001$.
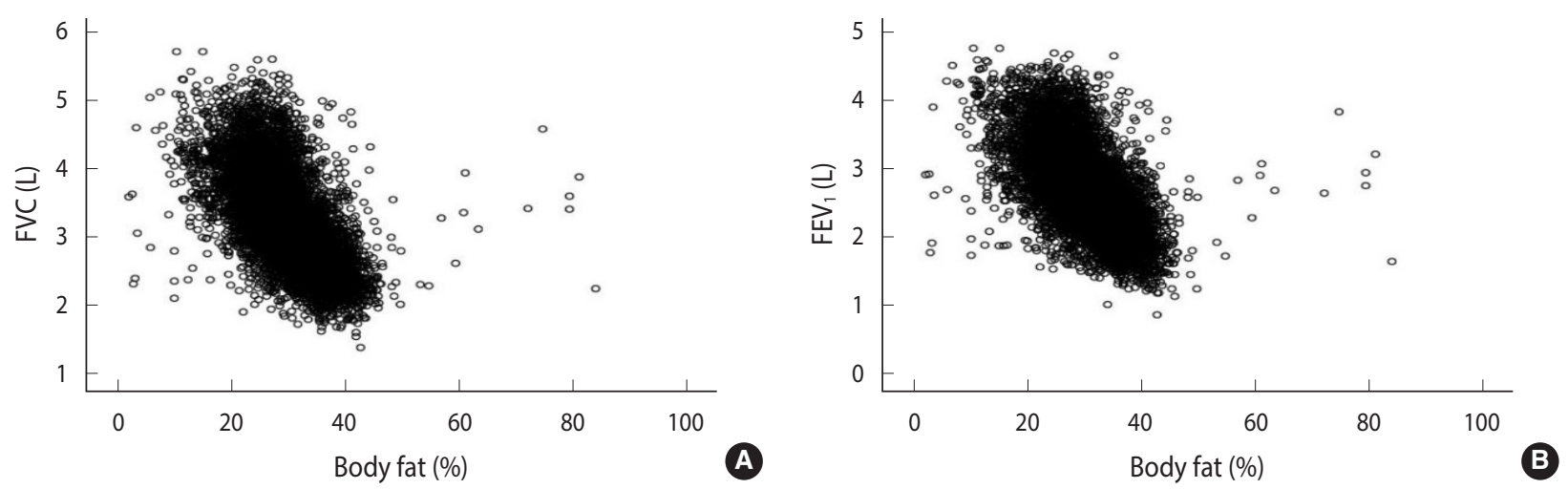

Figure 3. Spearman correlation analyses of the relationships among body fat percentage and lung function parameters such as FVC ( $A$; Spearman $\rho=-0.694, p<0.001)$ and $\mathrm{FEV}_{1}(B$; Spearman $\rho=-0.664, p<0.001)$ in the rural general adult Chinese population ( $\left.n=8,284\right)$. FVC, forced vital capacity; FEV ${ }_{1}$, forced expiratory volume in 1 second. 


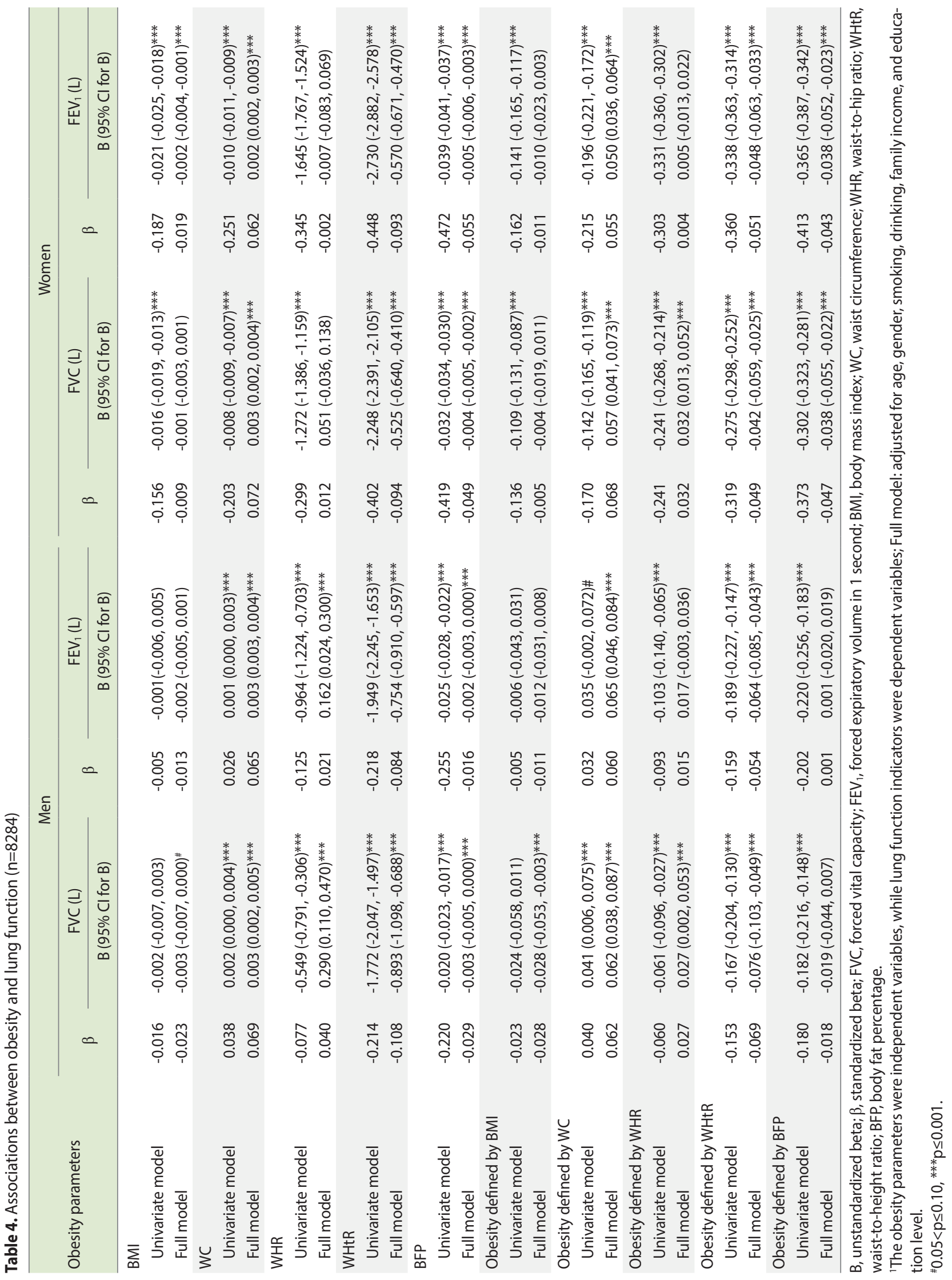


ly correlated with FVC and $\mathrm{FEV}_{1}$. However, both correlations were not significant in men, which is the most substantial difference when compared with women.

\section{Associations between obesity and lung function}

The associations between obesity and lung function in men and women are shown in Table 4. After adjustment for their respective confounding factors in the full multiple linear regression model, we found that BMI, WHtR, and BFP were negatively associated with $\mathrm{FVC}$ and $\mathrm{FEV}_{1}$. In contrast, WC and WHR were positively associated with FVC and $\mathrm{FEV}_{1}$ (Table 4). Specifically, BMI, $\mathrm{WHtR}$, and BFP were negatively associated with FVC $\left(\beta_{\mathrm{BMI}}=-0.001\right.$, $\left.\mathrm{p}<0.001 ; \beta_{\mathrm{WHtR}}=-0.525, \mathrm{p}<0.001 ; \beta_{\mathrm{BFP}}=-0.004, \mathrm{p}<0.001\right)$ and $\mathrm{FEV}_{1}\left(\beta_{\mathrm{BMI}}=-0.002, \mathrm{p}<0.001 ; \beta_{\mathrm{WHtR}}=-0.570, \mathrm{p}<0.001 ; \beta_{\mathrm{BFP}}=-0.005\right.$, $\mathrm{p}<0.001)$ in women. Similarly, WHtR and BFP were negatively associated with FVC $\left(\beta_{\mathrm{WHtR}}=-0.893, \mathrm{p}<0.001 ; \beta_{\mathrm{BFP}}=-0.003, \mathrm{p}<\right.$ $0.001)$ and $\mathrm{FEV}_{1}\left(\beta_{\mathrm{WHtR}}=-0.754, \mathrm{p}<0.001 ; \beta_{\mathrm{BFP}}=-0.002, \mathrm{p}<0.001\right)$ in men. However, WC was positively associated with FVC ( $\beta_{\mathrm{WC}}=$ $0.003, \mathrm{p}<0.001)$ and $\mathrm{FEV}_{1}\left(\beta_{\mathrm{WC}}=0.002, \mathrm{p}<0.001\right)$ in women. Additionally, WC and WHR were positively associated with FVC $\left(\beta_{\mathrm{WC}}=0.003, \mathrm{p}<0.001 ; \beta_{\mathrm{WHR}}=0.290, \mathrm{p}<0.001\right)$ and $\mathrm{FEV}_{1}\left(\beta_{\mathrm{WC}}=\right.$ $\left.0.003, \mathrm{p}<0.001 ; \beta_{\mathrm{WHR}}=0.162, \mathrm{p}<0.001\right)$ in men. The correlation and regression analyses showed consistent results regardless of gender (Tables 3 and 4).

Similarly, obesity defined by BMI, WHtR, and BFP was negatively associated with $\mathrm{FVC}$ and $\mathrm{FEV}_{1}$, whereas obesity defined by WC and WHR was positively associated with FVC and FEV (Ta- $^{-}$ ble 4). Obesity defined by BMI, WHtR, and BFP was negatively associated with FVC ( $\beta_{\text {obesity defined by BMI }}=-0.136, \mathrm{p}<0.001 ; \beta_{\text {obesity de- }}$ fined by WHtR $\left.=-0.049, \mathrm{p}<0.001 ; \beta_{\text {obesity defined by BFP }}=-0.047, \mathrm{p}<0.001\right)$ and $\mathrm{FEV}_{1}\left(\beta_{\text {obesity defined by BMI }}=-0.162, \mathrm{p}<0.001 ; \beta_{\text {obesity defined by WHtR }}=\right.$ $\left.-0.048, \mathrm{p}<0.001 ; \beta_{\text {obesity defined by } \mathrm{BFP}}=-0.038, \mathrm{p}<0.001\right)$ in women. Likewise, obesity defined by BMI and WHtR was negatively associated with FVC $\left(\beta_{\text {obesity defined by BMI }}=-0.028, \mathrm{p}<0.001 ; \beta_{\text {obesity defined by }}\right.$ $\left.{ }_{\text {wHtR }}=-0.069, \mathrm{p}<0.001\right)$ and $\mathrm{FEV}_{1}\left(\beta_{\text {obesity defined by BMI }}=-0.011, \mathrm{p}=0.235\right.$; $\left.\beta_{\text {obesity defined by } W H t R}=-0.054, \mathrm{p}<0.001\right)$ in men. Nevertheless, WC and WHR were positively associated with FVC $\left(\beta_{\text {obesity defined by } \mathrm{WC}}=0.057\right.$, $\left.\mathrm{p}<0.001 ; \beta_{\mathrm{WHR}}=0.032, \mathrm{p}<0.001\right)$ and $\mathrm{FEV}_{1}\left(\beta_{\text {obesity defined by } \mathrm{WC}}=0.055\right.$, $\left.\mathrm{p}<0.001 ; \beta_{\mathrm{WHR}}=0.005, \mathrm{p}=0.089\right)$ in women. Meanwhile, WC and WHR were positively associated with FVC $\left(\beta_{\text {obesity defined by } \mathrm{WC}}=0.062\right.$, $\left.\mathrm{p}<0.001 ; \beta_{\text {obesity defined by } \mathrm{WHR}}=0.027, \mathrm{p}<0.001\right)$ and $\mathrm{FEV}_{1}\left(\beta_{\text {obesity defined }}\right.$ by $\left.\mathrm{wC}=0.060, \mathrm{p}<0.001 ; \beta_{\text {obesity defined by WHR }}=0.017, \mathrm{p}=0.092\right)$ in men.

\section{DISCUSSION}

This study investigated the associations between obesity parameters and lung function in 8,284 adults from typical rural areas in central China. Our results showed a high prevalence of obesity, exceeding previously reported obesity rates in China. Although the prevalence of general obesity defined by height-related BMI and WHtR was not higher in women than in men, the prevalence of abdominal obesity defined by WC-related WC, WHR, and BFP was higher in women than in men. As expected, women had a lower level of lung function than men. Lung function was lower in the obesity groups than in the non-obesity groups for all definitions of obesity. Spearman correlation analyses showed that most of the obesity parameters were significantly correlated with the measured lung function indicators. After adjustment for potential confounders, WC-related parameters (e.g., WC and WHR) and obesity defined accordingly were positively associated with lung function parameters such as FVC and $\mathrm{FEV}_{1}$, while heightrelated obesity parameters (e.g., BMI, BFP, and WHtR) and obesity defined accordingly were negatively associated with lung function. Stratified by gender, overall, the association between general obesity and lung function was more evident in women than in men, while the link between central obesity and lung function was more obvious in men than in women.

Some previous studies have shown that obesity can alter chest wall mechanics, reduce lung volume, and increase airway resistance $[4,11,13]$. Nonetheless, inconclusive or inconsistent results have been reported regarding the associations between obesity parameters such as BMI and BFP and lung function indicators including $\mathrm{FVC}$ and $\mathrm{FEV}_{1}$, which may be due to previous studies' small sample sizes, heterogeneous obesity parameters, and specific groups $[19,21,44,45]$. In this study, we found that several parameters (e.g., BMI, WC, WHR, WHtR, BFP, and VFI) representing incremental degrees of obesity were negatively associated with lung function indicators, which is consistent with the results of most previous studies. According to previous reports, height, HC, and BM are positively associated with lung function levels. Our results suggested that the obesity groups had lower lung function levels than the non-obesity groups. In other words, individuals with obesity tended to have smaller lung capacity and lower lung function.

Some recent studies have proposed that WC-related parameters such as WHR and WHtR might be better indicators than BMI to assess the role of obesity in predicting lung function in a general Caucasian population [44-46]. In this study, we investigated the association between several obesity-related parameters and a series of lung function indicators in the general Han Chinese population with a large sample. Spearman correlation analyses and linear regression analyses both showed that elevated BMI, WHR, WHtR, BFP, and obesity defined by BMI, WHR, WHtR, and BFP were associated with lower lung function levels, such as FVC and $\mathrm{FEV}_{1}$. However, increased height, BM, WC, HC, and obesity defined by WC were associated with higher FVC and $\mathrm{FEV}_{1}$.

There seem to be some inconsistencies in the relationships between several obesity-related parameters, as presented above, and lung function in this study. A careful comparison of them provides a reasonable explanation for the differences; that is, height, weight, $\mathrm{WC}$, and $\mathrm{HC}$ are important factors related to lung function. Among them, height and WC are the 2 most important parameters in relation to lung function levels. Specifically, height is negatively related to certain obesity-related parameters such as BMI and WHtR, and obesity defined by BMI and WHtR was negatively associated with lung function because height is in the denominator of the 
formulas for BMI and WHtR and there is a positive relationship between height and lung function. Similarly, WHR is negatively related to $\mathrm{HC}$, and obesity defined by WHR was inversely linked with lung function partly because $\mathrm{HC}$ is in the denominator in the formula for WHR and there is a positive relationship between $\mathrm{HC}$ and lung function. Notably, WC, WHR (as a parameter positively related to WC), and obesity defined by WC and WHR were positively associated with lung function, since WC is in the numerator in the formula of WHR, and there was a positive relationship between WC and lung function.

According to the results of Spearman correlation analyses and linear regression analyses, the order of the closeness of the correlations of obesity parameters with lung function was as follows: (1) height $>$ weight $>\mathrm{HC}>\mathrm{WC}$; (2) WHtR $>\mathrm{BFP}>\mathrm{BMI}>\mathrm{WHR}$. It is well known that the height of adults remains constant over time. Therefore, weight, HC, and WC are the obvious and crucial parameters related to obesity in individuals during adulthood. Previous studies have shown that BMI and BFP (for general obesity) and WHR and WHtR (for central obesity) are recommended to assess the relationship between obesity and lung function. WC and obesity defined by WC and WHR were positively associated with FVC and $\mathrm{FEV}_{1}$, which may indicate that lung function improved with the increase of WC to some degree, which is consistent with the results of previous studies $[21,47,48]$. However, height, weight, and $\mathrm{HC}$ have a stronger influence on lung function than $\mathrm{WC}$, as manifested by the close relationships between obesity parameters, including WHtR, WHR, BMI, and lung function indicators such as FVC and $\mathrm{FEV}_{1}$.

Our findings indicate that several obesity-related parameters and obesity defined using those parameters were significantly associated with measures of lung function such as FVC and $\mathrm{FEV}_{1}$. The direction (inverse) of the effects of various obesity parameters (e.g., WHtR, WHR, BFP, and BMI) on lung function was similar, which suggests that obesity is significantly associated with lung damage. Systemic/limb/peripheral obesity defined by BMI, WHtR, and BFP was negatively associated with $\mathrm{FVC}$ and $\mathrm{FEV}_{1}$, while abdominal/belly/central obesity defined by WC and WHR was positively associated with FVC and $\mathrm{FEV}_{1}$. These results may suggest that taking only WC into account is inappropriate when investigating the relationship between obesity and lung function. In other words, it is better to define obesity using BMI, WHtR, and BFP than to use WC and WHR to evaluate their relationship with lung function.

It is worth mentioning that BMI was significantly associated with $\mathrm{FEV}_{1}$ in women, but not in men, according to linear regression analyses (Table 4), which is consistent with the higher correlation coefficient for BMI and lung function in women than in men (Table 3). In addition, this finding may be partly attributed to the larger sample size of women than that of men, as both men and women share the same direction of relationship between BMI and lung function. The finding of a positive association between WHR and lung function in men, but not in women, may be attributed to the higher WHR in men than in women (Table 2). A large WC and WC-related WHR may indicate a larger thoracic cavity and higher lung compliance and respiratory function [49]. Notably, there are some doubts regarding the stronger association of BFP and lung function in women than in men (Table 4). This is consistent with the higher BFP and correlation coefficients of BFP, WC, WHR, WHtR, VFI, and lung function in women than in men. Additionally, BFP is closely linked to subcutaneous and visceral fat, which mainly accumulates in the waist and abdomen. Compared with men, most rural women have a lower education and family income level, as well as birthing experience and subsequent body alterations, which may lead to a higher BFP than in men, in combination with a poor awareness of weight control and loss. There are differences in the distribution and level of BFP and its related parameters of muscle mass and strength between men and women; these differences may influence the contractility of respiratory muscles and subsequent respiratory function [50].

There were several strengths of our study. First, we recruited a large population sample of adults across a broad age range from a typical rural area in central China, which enabled us to derive insights into the prevalence of obesity and lung function levels in the rural area. Second, the analysis of several obesity parameters made it possible to comprehensively investigate their associations with lung function to obtain more accurate and detailed information. Third, the large sample size, assessment of potential confounders, and several effect models facilitated the investigation of the independent effects of peripheral and central obesity on lung function. However, several limitations of this study should be acknowledged. First, the cross-sectional nature of this study makes it difficult to draw causal conclusions between obesity and lung function. Second, although several important factors were taken into account in the analyses, there remains a possibility of residual confounding caused by other unmeasured variables, such as muscle mass and strength, metabolic factors, markers of inflammation, nutritional status, and history or indicators of allergy. Third, it is necessary to determine whether these results are generalizable to other ethnic populations for further investigation.

In summary, both general and central obesity are negatively associated with lung function in the general Chinese rural adult population. There was an inverse effect of WC-related WHR and height-related WHtR on lung function. In particular, height-related obesity parameters, such as BMI and WHtR, had negative associations with lung function, whereas WC-related obesity parameters, such as WC and WHR, had positive associations with lung function. Given the inverse association between BFP and lung function, BMI (for general obesity) and WHtR (for central obesity) may be the preferred parameters to assess the relationship between obesity and lung function in the general population. Individuals with obesity and higher values of obesity-related parameters had lower lung function levels. Compared with men, the exacerbation of obesity was more closely associated with declining lung function in women. However, the underlying mechanism between these relationships needs further investigation. 


\section{SUPPLEMENTARY MATERIALS}

Supplementary materials are available at http://www.e-epih.org/.

\section{CONFLICT OF INTEREST}

The authors have no conflicts of interest to declare for this study.

\section{FUNDING}

This work was supported by the research grants of the National Key Research and Development Program Precision Medicine Initiative of China (2016YFC0900803), the Postdoctoral Research Foundation of China (2020M683183), and the Natural Science Foundation of Henan Province of China (202300410313).

\section{ACKNOWLEDGEMENTS}

The authors are grateful to the recruited subjects for participating in this project. We also thank Dr. Diana A. van der Plaat for her constructive comments and language editing.

The funding sources were not involved in the study design, data collection, analysis, and interpretation, or in writing and submitting the manuscript.

\section{AUTHOR CONTRIBUTIONS}

Conceptualization: XZ, WW. Data curation: XZ, DL. Formal analysis: XZ. Funding acquisition: XZ, DL, WW. Methodology: XZ, DL, WW. Project administration: WW. Visualization: XZ. Writing - original draft: XZ, DL. Writing - review \& editing: XZ. DL, ZA, HL, JS, WW.

\section{ORCID}

Xiang Zeng: https://orcid.org/0000-0001-8252-3558; Dongling Liu: https://orcid.org/0000-0003-1583-7682; Zhen An: https://orcid.org/0000-0002-1651-0924; Huijun Li: https://orcid.org/00000001-6765-2028; Jie Song: https://orcid.org/0000-0002-8570-2380; Weidong Wu: https://orcid.org/0000-0002-7334-8679

\section{REFERENCES}

1. Ng M, Fleming T, Robinson M, Thomson B, Graetz N, Margono $\mathrm{C}$, et al. Global, regional, and national prevalence of overweight and obesity in children and adults during 1980-2013: a systematic analysis for the Global Burden of Disease Study 2013. Lancet 2014; 384:766-781.

2. Kelly T, Yang W, Chen CS, Reynolds K, He J. Global burden of obesity in 2005 and projections to 2030. Int J Obes (Lond) 2008; 32:1431-1437.

3. Lim SS, Vos T, Flaxman AD, Danaei G, Shibuya K, Adair-Rohani $\mathrm{H}$, et al. A comparative risk assessment of burden of disease and injury attributable to 67 risk factors and risk factor clusters in 21 regions, 1990-2010: a systematic analysis for the Global Burden of Disease Study 2010. Lancet 2012;380:2224-2260.

4. Forno E, Han YY, Mullen J, Celedón JC. Overweight, obesity, and lung function in children and adults-a meta-analysis. J Allergy Clin Immunol Pract 2018;6:570-581.e10.

5. Flegal KM, Kit BK, Orpana H, Graubard BI. Association of allcause mortality with overweight and obesity using standard body mass index categories: a systematic review and meta-analysis. JAMA 2013;309:71-82.

6. Jaacks LM, Gordon-Larsen P, Mayer-Davis EJ, Adair LS, Popkin B. Age, period and cohort effects on adult body mass index and overweight from 1991 to 2009 in China: the China Health and Nutrition Survey. Int J Epidemiol 2013;42:828-837.

7. He Y, Pan A, Wang Y, Yang Y, Xu J, Zhang Y, et al. Prevalence of overweight and obesity in 15.8 million men aged $15-49$ years in rural China from 2010 to 2014. Sci Rep 2017;7:5012.

8. Wu J, Xu H, He X, Yuan Y, Wang C, Sun J, et al. Six-year changes in the prevalence of obesity and obesity-related diseases in Northeastern China from 2007 to 2013. Sci Rep 2017;7:41518.

9. Xi B, Liang Y, He T, Reilly KH, Hu Y, Wang Q, et al. Secular trends in the prevalence of general and abdominal obesity among Chinese adults, 1993-2009. Obes Rev 2012;13:287-296.

10. McClean KM, Kee F, Young IS, Elborn JS. Obesity and the lung: 1. Epidemiology. Thorax 2008;63:649-654.

11. Dixon AE, Peters U. The effect of obesity on lung function. Expert Rev Respir Med 2018;12:755-767.

12. Melo LC, Silva MA, Calles AC. Obesity and lung function: a systematic review. Einstein (Sao Paulo) 2014;12:120-125.

13. Mafort TT, Rufino R, Costa CH, Lopes AJ. Obesity: systemic and pulmonary complications, biochemical abnormalities, and impairment of lung function. Multidiscip Respir Med 2016;11:28.

14. Salome CM, King GG, Berend N. Physiology of obesity and effects on lung function. J Appl Physiol (1985) 2010;108:206-211.

15. Tomescu DR, Popescu M, Dima SO, Bacalbașa N, Bubenek-Turconi S. Obesity is associated with decreased lung compliance and hypercapnia during robotic assisted surgery. J Clin Monit Comput 2017;31:85-92.

16. Chen Y, Horne SL, Dosman JA. Body weight and weight gain related to pulmonary function decline in adults: a six year follow up study. Thorax 1993;48:375-380.

17. Stenius-Aarniala B, Poussa T, Kvarnström J, Grönlund EL, Ylikahri M, Mustajoki P. Immediate and long term effects of weight reduction in obese people with asthma: randomised controlled study. BMJ 2000;320:827-832.

18. Peralta GP, Marcon A, Carsin AE, Abramson MJ, Accordini S, Amaral AF, et al. Body mass index and weight change are associated with adult lung function trajectories: the prospective ECRHS study. Thorax 2020;75:313-320.

19. Liu X, Mao Z, Li Y, Wu W, Zhang X, Huo W, et al. Cohort profile: the Henan rural cohort: a prospective study of chronic non-communicable diseases. Int J Epidemiol 2019;48:1756-1756j.

20. Pan J, Xu L, Lam TH, Jiang CQ, Zhang WS, Jin YL, et al. Associa- 
tion of adiposity with pulmonary function in older Chinese: Guangzhou Biobank Cohort Study. Respir Med 2017;132:102-108.

21. Yao TC, Tsai HJ, Chang SW, Chung RH, Hsu JY, Tsai MH, et al. Obesity disproportionately impacts lung volumes, airflow and exhaled nitric oxide in children. PLoS One 2017;12:e0174691.

22. Chen YY, Kao TW, Fang WH, Wang CC, Chang YW, Yang HF, et al. Body fat percentage in relation to lung function in individuals with normal weight obesity. Sci Rep 2019;9:3066.

23. Trang LT, Trung NN, Chu DT, Hanh NT. Percentage body fat is as a good indicator for determining adolescents who are overweight or obese: a cross-sectional study in Vietnam. Osong Public Health Res Perspect 2019;10:108-114.

24. World Health Organization Western Pacific Region. The Asia-Pacific perspective: redefining obesity and its treatment; 2000 [cited 2021 May 1]. Available from: https://apps.who.int/iris/handle/ $10665 / 206936$.

25. Goonasegaran AR, Nabila FN, Shuhada NS. Comparison of the effectiveness of body mass index and body fat percentage in defining body composition. Singapore Med J 2012;53:403-408.

26. Tan CE, Ma S, Wai D, Chew SK, Tai ES. Can we apply the National Cholesterol Education Program Adult Treatment Panel definition of the metabolic syndrome to Asians? Diabetes Care 2004; 27:1182-1186

27. Jia A, Xu S, Ming J, Xing Y, Guo J, Zhao M, et al. Body fat percentage cutoffs for risk of cardiometabolic abnormalities in the Chinese adult population: a nationwide study. Eur J Clin Nutr 2018; 72:728-735.

28. Du P, Wang HJ, Zhang B, Qi SF, Mi YJ, Liu DW, et al. Prevalence of abdominal obesity among Chinese adults in 2011. J Epidemiol 2017;27:282-286.

29. Torun E, Cakir E, Ozgüç F, Ozgen IT. The effect of obesity degree on childhood pulmonary function tests. Balkan Med J 2014;31: 235-238.

30. Winck AD, Heinzmann-Filho JP, Soares RB, da Silva JS, Woszezenki CT, Zanatta LB. Effects of obesity on lung volume and capacity in children and adolescents: a systematic review. Rev Paul Pediatr 2016;34:510-517.

31. Davidson WJ, Mackenzie-Rife KA, Witmans MB, Montgomery MD, Ball GD, Egbogah S, et al. Obesity negatively impacts lung function in children and adolescents. Pediatr Pulmonol 2014;49: 1003-1010.

32. Littleton SW. Impact of obesity on respiratory function. Respirology 2012;17:43-49.

33. Low S, Chin MC, Ma S, Heng D, Deurenberg-Yap M. Rationale for redefining obesity in Asians. Ann Acad Med Singap 2009;38:66-69.

34. Sutherland TJ, McLachlan CR, Sears MR, Poulton R, Hancox RJ. The relationship between body fat and respiratory function in young adults. Eur Respir J 2016;48:734-747.

35. Leone N, Courbon D, Thomas F, Bean K, Jégo B, Leynaert B, et al. Lung function impairment and metabolic syndrome: the critical role of abdominal obesity. Am J Respir Crit Care Med 2009;179: 509-516.

36. Lin WY, Yao CA, Wang HC, Huang KC. Impaired lung function is associated with obesity and metabolic syndrome in adults. Obesity 2006;14:1654-1661.

37. Pan WH, Yeh WT. How to define obesity? Evidence-based multiple action points for public awareness, screening, and treatment: an extension of Asian-Pacific recommendations. Asia Pac J Clin Nutr 2008;17:370-374.

38. Bhatti U, Laghari ZA, Syed BM. Effect of body mass index on respiratory parameters: a cross-sectional analytical study. Pak J Med Sci 2019;35:1724-1729.

39. Quanjer PH, Stanojevic S, Cole TJ, Baur X, Hall GL, Culver BH, et al. Multi-ethnic reference values for spirometry for the 3-95-yr age range: the global lung function 2012 equations. Eur Respir J 2012;40:1324-1343.

40. Hu L, Huang X, You C, Li J, Hong K, Li P, et al. Prevalence of overweight, obesity, abdominal obesity and obesity-related risk factors in southern China. PLoS One 2017;12:e0183934.

41. Zeng X, Liu D, Zhao X, Chao L, Li Y, Li H, et al. Association of bone mineral density with lung function in a Chinese general population: the Xinxiang rural cohort study. BMC Pulm Med 2019;19:239.

42. Ip MS, Ko FW, Lau AC, Yu WC, Tang KS, Choo K, et al. Updated spirometric reference values for adult Chinese in Hong Kong and implications on clinical utilization. Chest 2006;129:384-392.

43. Backman H, Eriksson B, Hedman L, Stridsman C, Jansson SA, Sovijärvi A, et al. Restrictive spirometric pattern in the general adult population: methods of defining the condition and consequences on prevalence. Respir Med 2016;120:116-123.

44. Ochs-Balcom HM, Grant BJ, Muti P, Sempos CT, Freudenheim JL, Trevisan M, et al. Pulmonary function and abdominal adiposity in the general population. Chest 2006;129:853-862.

45. Bekkers MB, Wijga AH, de Jongste JC, Kerkhof M, Postma D, Gehring U, et al. Waist circumference, BMI, and lung function in 8-year-old children: the PIAMA birth cohort study. Pediatr Pulmonol 2013;48:674-682.

46. Canoy D, Luben R, Welch A, Bingham S, Wareham N, Day N, et al. Abdominal obesity and respiratory function in men and women in the EPIC-Norfolk Study, United Kingdom. Am J Epidemiol 2004;159:1140-1149.

47. Chen Y, Rennie D, Cormier Y, Dosman JA. Waist circumference associated with pulmonary function in children. Pediatr Pulmonol 2009;44:216-221.

48. Cibella F, Bruno A, Cuttitta G, Bucchieri S, Melis MR, De Cantis $S$, et al. An elevated body mass index increases lung volume but reduces airflow in Italian schoolchildren. PLoS One 2015;10: e0127154.

49. Zeng X, Xu X, Zhang Y, Li W, Huo X. Chest circumference and birth weight are good predictors of lung function in preschool children from an e-waste recycling area. Environ Sci Pollut Res Int 2017;24:22613-22621.

50. Flegal KM, Shepherd JA, Looker AC, Graubard BI, Borrud LG, Ogden CL, et al. Comparisons of percentage body fat, body mass index, waist circumference, and waist-stature ratio in adults. Am J Clin Nutr 2009;89:500-508. 